Pteridines

Vol. 10, 1999, pp. $178-189$

\title{
Ranopterins-Amphibia Skin Pteridines Displaying Hematopoietic, Immunomodulatory, and Macrophageal Proliferative Biological Activities*
}

\author{
Elissaveta Zvetkova
}

Institute of Experimental Morphology and Anthropology, Bulgarian Academy of Sciences, Sofia, Bulgaria

(Received October 1, 1999)

\section{Introduction}

Unconjugated pteridines-xanthopterin, isoxanthopterin, leukopterin, etc., are found in high concentrations as pigments in insects, amphibia, reptiles and fish (1-7). As early as 1929, A. I. Hadjioloff described for the first time dermal structures (layers) and bright pigment cells with proper fluorescence in the amphibian and fish skin (see also refs. 8-12) which later led to the discovery of their pteridines content (13-19). Efforts have simultaneously been aimed at the morphological localization of these luminescent phenomena, their physico-chemical exploration and biochemical identification together with the precise definition of the luminophores, their isolation, purification, and assessment of their possible biological activities and feasible therapeutic application (2026). In the cases of fluorescent substances isolated and purified from amphibia and frog skin-ranopterins $(20,21,26)$-as well as these isolated from the skin of fish-ichtiopterins $(12,13)$-the results of 60 years Bulgarian school studies were presented in a monograph of A. I. Hadjioloff and E. Zvetkova (27).

Pteridines-containing dermal pigment cells - chromatophores in amphibian (Rana ridibunda and Rana agilis) skin: cytochemical, ultrastructural and histo-autoradiographical characteristics

The morphological and functional changes in the

* This paper is dedicated on the memory of my teacher Acad. Assen Ivanov Hadjioloff and my brother Inj. Ivan Borissov Zvetkov frog and toad skin pigmentation are determined by the presence of the dermal color pigment cells-chromatophores and by their cellular interactions $(8,20$, $28,29)$. Depending on the color of their cytoplasmic pigments, the chromatophores belong to several groups (Hadjioloff's classification; ref. 8), namely: black (melanin-containing)-melanophores; white and brown (guanine-containing)-guanophores; blue, yellow and red (pteridines-containing)-cyanophores, xanthophores and erythrophores. By means of lightand electron microscopy the following types of chromatophores were distinguished in the amphibian derma (30-41): melanophores with specific melanincontaining cytoplasmic differentiations-melanosomes; guanophores with cytoplasmic reflecting plates-at the places of the extracted guanine crystals and pteridines-containing with which properties this review deals briefly.

The data from our ultrastructural investigations on the dermal pteridine-containing chromatophores in Rana ridibunda and Rana agilis skin (40) demonstrated the presence of specific cytoplasmic differentiation-pterinosomes. These specific organelles were first described in toad skin by Matsumoto et al. (37) as round or oval pigment granules sized from $0.5 \mu$ to $l \mu$ and consisting of different numbers of concentric electron-dense elementary lamellae which, in their turn, consist of elementary granules. These cytoplasmic differentiations organels which vary in size in the by us examined two species-Rana ridibunda and Rana agilis - are also different in the electron density of their elementary lamellae: from faintly outlined to highly osmiophillic ones which frequently form an electron-dense center or more 


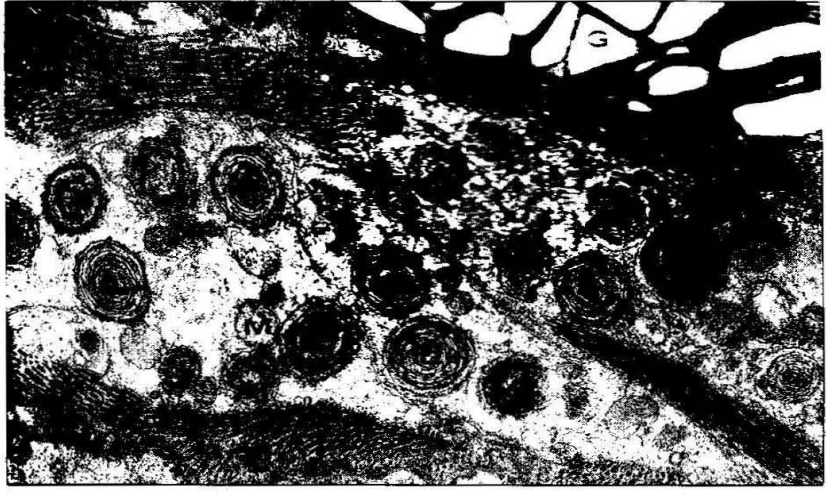

Figure 1. Electron microscopic picture of chromatophores in the derma of Rana esculenta: guanophore (G); light coloured pigment cell with specific pteridines-containing cytoplasmic structures-pterinosomes (Pt) composed of concentric lamellae; M-mitochondria; L-lipid drops (Hitachi electron microscope, $\times 15,000)$.

compact periphery (Fig. 1). There are also entirely electron-dense (osmiophyllic) pterinosomes with unclear lamellar structure some of which are similar to melanosomes (Fig. 2). We assumed that the differentiation of pterinosomes begins from unclearly outlined elementary lamellae, passes through more strongly osmiophyllic ones to fully differentiated organelles with greater electron density and unclearly outlined lamellar structure. Varying in size mitochondria, glycogen granules, lipid droplets with medium electron density and fine granularity (carotinosomes) and a smooth endoplasmic reticulum were also soon established in the cytoplasm of dermal bright colored chromatophores in the two amphibia species examined (Figs. 1, 2). The well developed smooth endoplasmic reticulum in these

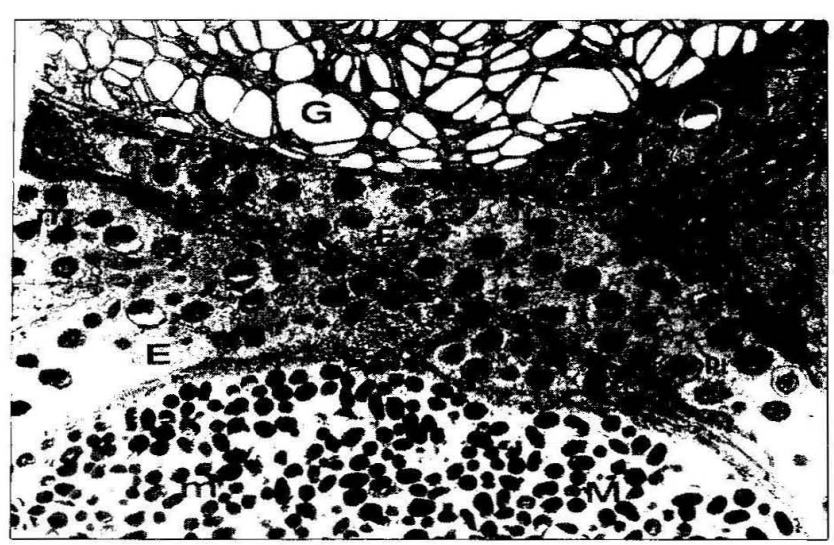

Figure 2. Electronogram of guanophore $(\mathrm{G})$ with extracted guanine crystals in the cytoplasm; red pigment cellserythrophores (E) with cytoplasmic lamellar structures, pterinosomes $(\mathrm{Pt})$ and melanophore $(\mathrm{M})$ with melanosomes $(\mathrm{M})$ in the cytoplasm. One could see melanosome-like structures $(\mathrm{m})$ in the cytoplasm of eryhrophores (Hitachi clectron microscope, $\times 6,500)$. cell which frequently forms vesicles, is probably responsible for the glycogen and carotinoid synthe$s$ is in the dermal xanthophores, cyanophores and erythrophores $(29,37,41)$.

The guanine-containing cytoplasmic differentiations (crystal-like formations) in the guanophores were denominated by certain authors as iridosomes $(29,30,31,37,41)$. In this cell type mitochondria are also well presented and localized between the guanine crystals, in the so-called by us "interstitial cytoplasm". The last two classes of chromatophorescontaining pteridines and guanine - are interesting from the biochemical point of view by means of isolation and purification of biologically and pharmacologically active substances which might be found in their specific cytoplasmic differentiations organelspterinosomes and iridosomes. From this point of view the histophysiology of amphibian skin fluorescent layers and pigment cells is of great interest and some histo-autoradiographic studies on the genesis of their pigments were carried out $(27,42-45)$. By means of the histo-autoradiographic method the incorporation of biogenic amines and their precursors in the Rana ridibunda skin pigment cells was investigated. Measuring the dynamics of incorporation of ${ }^{3} \mathrm{H}$-labelled tyrosine and dopamine in the skin melanophores and melanocytes, only tyrosine (L-3.5${ }^{3} \mathrm{H}$ tyrosine; specific activity $42 \mathrm{Ci} / \mathrm{mM}$, Amersham, Great Britain) and tryptophan (L-G- ${ }^{3} \mathrm{H}$ tryptophan; specific activity $8.8 \mathrm{Ci} / \mathrm{mM}$, Amersham) incorporation could be detected in the bright-colored pigment cells-containing guanine in their cytoplasmic organels-iridosomes and chromatophores containing pteridines in their pterinosomes. The results obtained by us are probably related to certain common stages in the synthesis of melanine and other color pigments, including pteridines in the chromatophores of lower vertebrates and are in support of our ultrastructural data about the simultaneous presence of pterinosomes and melanosomes in some pigment cells of amphibian dermis (40). We supposed that the intense incorporation of labelled tryptophan in amphibia skin chromatophores could be a sensitive biological marker of their pteridines biosynthesis, which is related to the intracellularly-induced tryptophan degradation (46).

Isolation and purification of ranopterins from the dermal chromatophores of amphibia (Rana ridibunda)

Skins of Rana ridibunda were homogenized in $50 \%$ methanol solution (in a Yoring Blender). The supernatant was distilled under vacuum until the separation of the methanol and condensed to $1 / 10$ 
of the initial volume. Pteridines were purified by gel chromatography on Sephadex Gl, on a column 40 $\mathrm{mm} / 600 \mathrm{~mm}$ (realized by A. Dikov with the aid of W. Pfleiderer; the method of pteridines purification was described by Hadjioloff et al., ref. 43 ; and by Shivatcheva, Hadjioloff and Dikov, ref. 47). After lyophilization of the effluent four pteridine fractions were identified by their chemical reactivity and ultraviolet absorption spectra: the fractions with a maximal fluorescence at $254 \mathrm{~nm}$. were collected and concentrated in a rotation vacuum evaporator at $35^{\circ} \mathrm{C}$ (47). The highly concentrated material was applied to plaques for preparative thin layer chromatography, covered with cellulose and separated in a butanol:water:ammonia system. The material from many plaques was collected and the pterin fractions were extracted with $30 \%$ solution of acetic acid. The following four fractions were identified: isoxanthopterin, neopterin, pterin-6-carboxylic acid (Pt-6$\mathrm{COOH})$ and biopterin. First attempts in this direction in Bulgaria were made by Hadjioloff and Atsev (20) and Atzev and Hadjioloff (21) who isolated in 1968 only one pteridine derivative from the skin of Rana ridibunda. An analogous substance (ichthyopterin) was synthesized by Tschesche and Korte in 1951 (48); the blue fluorescence of ichthyopterincontaining chromatophores in the skin of fish was examined by fluorescent microscopy earlier by Hadjioloff and $\mathrm{K}$ restev (12). Two of ranopterin fractions obtained by Dikov et al. $(43,47)$ - neopterin and Pt-6-COOH - were tested for their biological activities by us in the last decade.

On the biological activities of ranopterins: in vitro and in vivo studies

The first isolated ranopterin fraction identified by Atsev and Hadjioloff (21), and given to experimental rats, influenced proliferation and differentiation processes in bone marrow and other hematopoietic organs: accelerated the development of the youngest hemoblastic cells and delayed their differentiation. A rapidly emerging proliferative reaction, with appearance of activated reticular cells and lymphoplasmocytes (plasmoblasts, proplasmocytes), was established in lymph nodes of experimental mice after the exogenous pteridine/ranopterin treatment in vivo and in vitro, by some fractions of ranopterins isolated by A.Dikov $(43,47)$. Pteridine fractions neopterin and Pt-6-COOH isolated from the chromatophores of Rana ridibunda skin were tested in vitro and in vivo in different experimental models (49-55). The results obtained demonstrated their hematopoietic, immunomodulatory and bone marrow macrophage/stro- mal cells-proliferative activities.

The hematopoietic activity of the ranopterin fraction $(\mathrm{Pt}-6-\mathrm{COOH})$ was tested in vitro-in conditions of murine bone marrow agar cultures $(49,50)$. Upon testing the pteridine fraction has been added to the agar cultures medium at doses of $10,25,50$ and $100 \mu \mathrm{g} / \mathrm{ml}$. The cell types present in the colonies and clusters were cytologically and cytochemically characterized after in situ staining (in agar cultures) for DNP, RNP and basic proteins (56). The results show a well expressed macrophagealgranulocyte colony-stimulating activity (MG-CSA) of the exogenously added ranopterin fraction Pt-6$\mathrm{COOH}$ (Fig. 3). As to the induction of myeloid cell proliferation the maximum effect was established upon Pt-6-COOH application at a dose of $25-50 \mu \mathrm{g} /$ $\mathrm{ml}$ culture medium. The MG-CSA of Pt-6-COOH in mouse bone marrow agar cultures is probably due to the effect of this biologically active substance on the proliferation and differentiation of the early bone marrow progenitors from the macrophage/ granulocyte series. The problem whether the molecular and cellular mechanisms of the in vitro hematopoietic effects of $\mathrm{Pt}-6-\mathrm{COOH}$ are similar to the ones of hematopoietic growth factors is suitable for further investigations. It is possible that exogenously

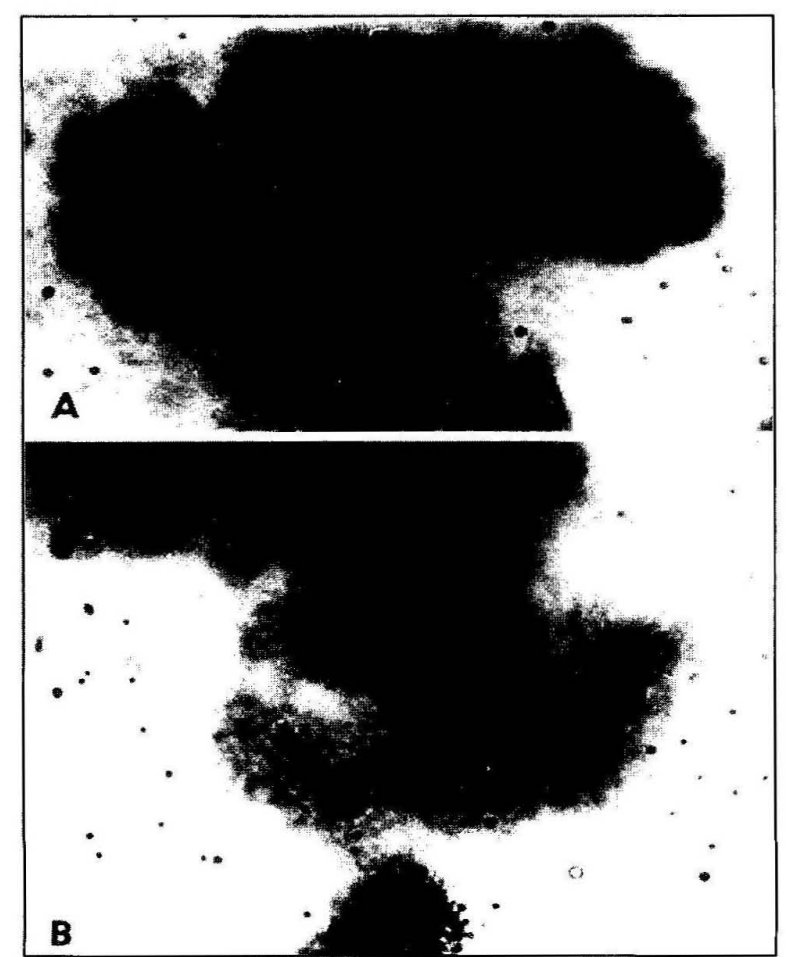

Figure 3. A: Macrophageal (M-) colonx; B: macrophageal/ granulocyte (MG-) colont: in murine bone marrow agar cultures stimulated by $\mathrm{Pt}-6 . \mathrm{COOH}$, Staining in agar, ref. $56 ; \times 1,250$-immercion 
added Pt-6-COOH penetrates through the cellular and nuclear membranes influencing differentiation of granulocytes/macrophages from their bone marrow progenitors $(49,50,57)$. In our previous studies we also established a presence of MG-CSA in the supernatants from mouse long-term bone marrow cultures exogenously treated with two ranopterin fractions $\mathrm{Pt}-6-\mathrm{COOH}$ and neopterin (54).

In the neopterin treated (at doses $20-50 \mu \mathrm{g} / \mathrm{ml}$ ) liquid short- and long-term mouse bone marrow cultures, a shift in the cellular composition was observed as early as the $3^{\text {rd }}$ day of cultivation (51). The cytological (cytocentrifugal/cytospin) preparations prevailed small- and medium-sized, peroxidase positive- and phagocytically inactive macrophages. In the cytoplasm of these small immature bone marrow macrophages one can see a positive reaction for basic (fast green positive-) cytoplasmic proteins as well as strongly expressed NOS-activity $(51,52$, and Zvetkova et al., unpublished).

In the stromal layers of neopterin-treated longterm mouse bone marrow cultures one could see hematopoietic islets among stromal cells stained on the plastic. Our results obtained on the bone marrow stromal macrophages proliferation under the exogenous in vitro treatment by ranopterin neopterin could serve as a subject for further discussions and may be of practical importance, having in mind the role of bone marrow stromal cells in the entire hematopoiesis. In this respect it is interesting to note that in murine erythroleukaemia cells tetrahydrobiopterin synthesis has been demonstrated to be functionally connected with cell proliferation (58). The pioneers in this field of investigations, Jacobson and Simpson (59), first described the possible use of pteridines in the elucidation of antipernicious anemia factor.

Using small doses of ranopterin neopterin in our in vitro model system (exogenously added neopterin, at doses $10-25 \mathrm{mg} / \mathrm{ml}$ medium, to the liquid mouse bone marrow cultures) we observed from $96 \mathrm{~h}$ to day 7 of cultivation that bone marrow stromal cellsstromal macrophages and fibroblast-like cells- considerably enhanced their adhesiveness, forming abundant cytoplasmic protrusions and synthesizing extracellular matrix, probably containing fibronectin and/or other cell adhesion molecules (Fig. 4; E. Zvetkova, E. Katzarova, Sv. Petkova, unpublished). The formation of cytoplasmic protrusions and the production of extracellular matrix with high adhesivenes by bone marrow stromal cells may be interpreted as one sign of bone marrow stromal activation (51) which is probably of importance in some pathological cases of enhanced or reduced marrow

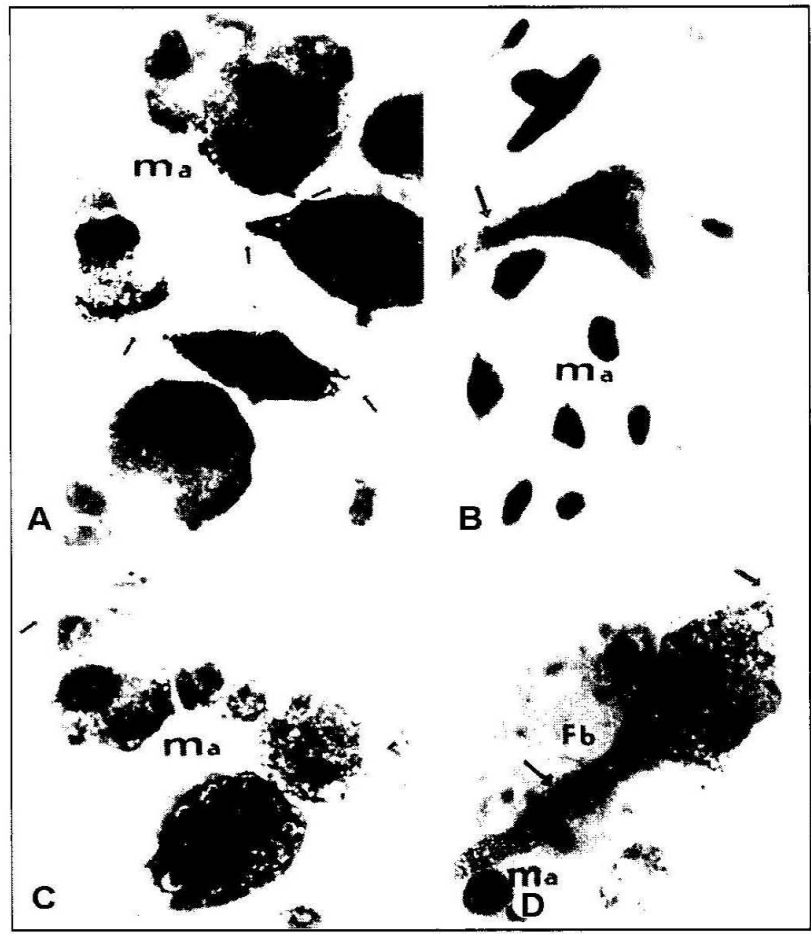

Figure 4. Bone marrow stromal cells stained in the bottom of the flask in the long term bone marrow cultures, treated in vitro by $25 \mu \mathrm{g} / \mathrm{ml}$ ranopterin-neopterin $(\mathrm{A}, \mathrm{B}, \mathrm{D})$ and br $50 \mu \mathrm{g} / \mathrm{ml}$ (C): Ma-macrophages differing in size and degree of cell activation (A-C) and with apoptotic nuclei (C-arrowheads); intercellular (FN-) matrix (A-arrows); fibroblast-like cell with a long cytoplasmic dentrit-like uropode (D - arrow). Staining by the method of Zvetkova and Zvetkov, (ref. 99; $\times 1,250$-immersion).

hematopoietic functions as well as in cases of bone marrow transplantation (60). In this line of thoughts and having in mind ours and others experimental results $(60,61)$ confirming that fibronectin and other molecules of high adhesiveness in the bone marrow matrix produce better blood cell differentiation we suggest that low doses of exogenously applied ranopterin neopterin could be suitable for improving the adhesive and motility properties not only of the normal hematopoietic cells but probably of the leukemic ones (E. Zvetkova, E. Katzarova, Sv. Petkova, unpublished). We also obtained that exogenously added ranopterin neopterin at higher doses (50-100 $\mu \mathrm{g} / \mathrm{ml}$ culture medium) could act as an apoptosis-inducing factor (E. Zvetkova, unpublished).

In the literature there are other interesting facts concerning cell adhesion phenomena and mononuclear cells expression of surface adhesion molecules such as MAC-1, an active integrin, involved in triggering the neutrophils adhesion to endothelial cells (62). On the one hand, the higher expression of adhesion molecules on lymphocytes and monocytes in various diseases is relevant in the activated immune 
mechanisms leading to organ damage; on the other hand, the expression/overexpression of some surface adhesion molecules is inducible by inflammatory cytokines like interleukin- 1 and tumor necrosis factor(TNF)- $\alpha$ mainly secreted by the monocyte/macrophage system producing also large amounts neopterin as a sensitive indicator of activated cell-mediated immune response $(63,64)$. Instead of the fact that in some cases of chronic immune activation the concentrations of neopterin were not related to the adhesion molecules levels (64) the probable involvement of immunocompetent cells in the production of both neopterin and adhesion molecules could be further discussed in the light of data that $\mathrm{TNF}-\alpha$ synergistically amplifies macrophages for neopterin secretion (46) and that like neopterin, the soluble receptors for $\mathrm{TNF}$ are parameters of cell-mediated immune activation (65-67).

The activation of the adhesion phenomena has been also observed locally in the amphibian (Rana esculenta) skin-e.g. in the first described by Hadjioloff (8) and so-called "fibronectin pathways" (68) for pigment cell migration in the dermal tract of the frog skin. These vertical tracts (Fig. 5) connected the dermal stratum spongiosum with subcutaneous tissue (see also refs. 22-25, 27). The fibronectin tracts in the frog skin contained fibronectin-outlined flattened pigmentary cells and fibroblasts (68). In the organ/tissue cultures, both pigmentary cells and fibroblasts disappeared from the vertical dermal fibronectin-tracts when antiserum to fibronectin was added to the culture medium. The data of Denefle et al. (68) suggested that the vertical tracts in the frog skin are involved in the migration of both cell

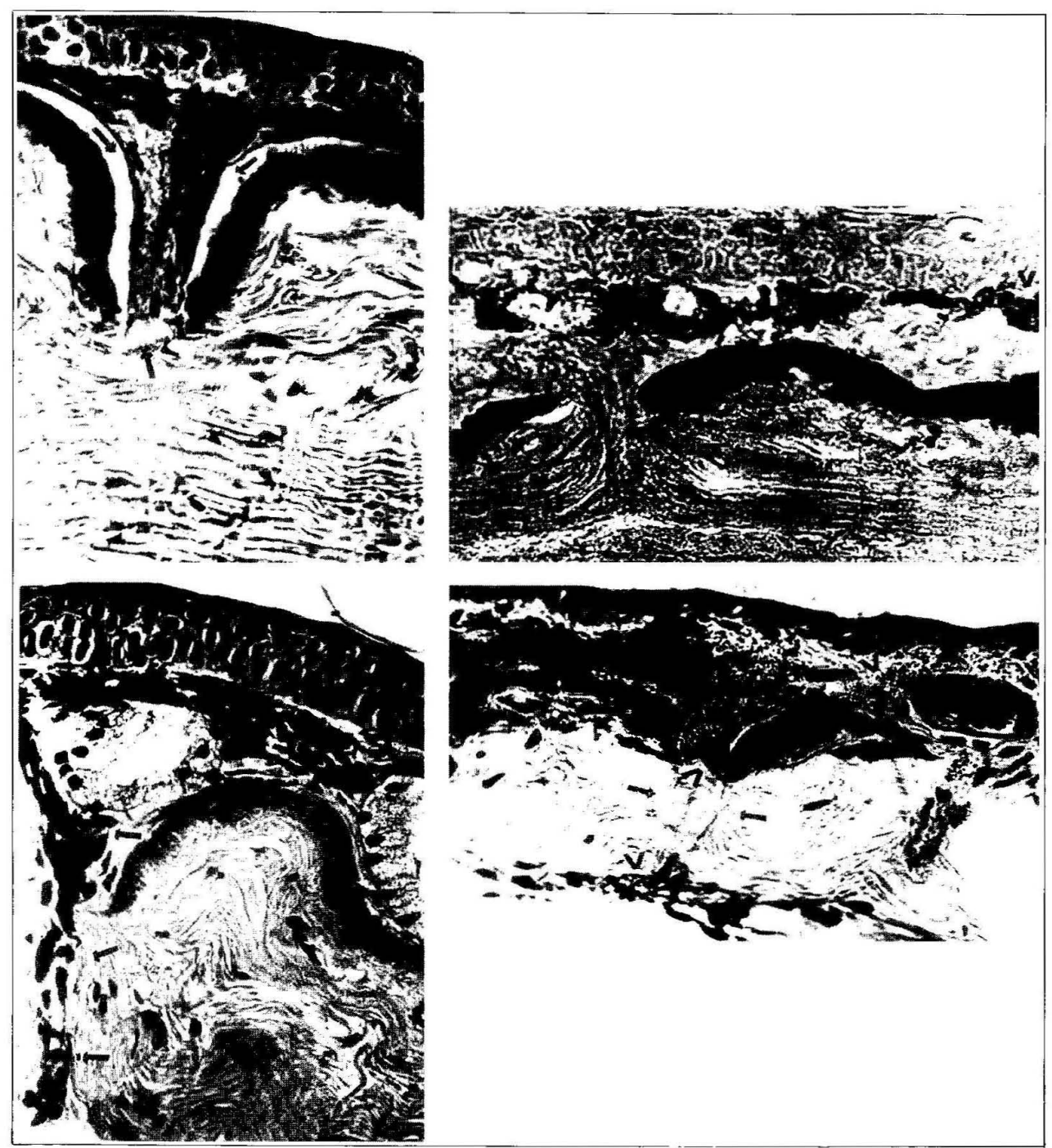

Figure 5. Dorsal (left panel) and ventral (right panel) skin of Rana rilihimeic: Fibronectin (FN-) tracts-arrows; one can see melanophophores-in the dorsal skin; bright pigment cells-chromatophores and guanophores (arowheads) are well presented in the ventral skin (staining by hematoxyline-eosine; $\times 300$. 
apes. In such cases one could speculate about the probable role of chromatophores and their pteridines content in the cellular mechanisms of fibronectin production. We supposed (in the light of our recent experimental data) that the fibronectin-outlined fibroblasts in the amphibian fibronectin dermal tracts could be stimulated for their fibronectin production by pteridines-dispersed as pterinosomes from the pteridines-containing dermal chromatophores in the extracellular space-between neighbouring fibroblasts. Moreover, Denefle et al. (68) also observed dispersed melanosomes from the cytoplasms of elongated melanophores. The melanophore migration observed by Iwata et al., (69) in the scales of the fish medaka showed the same pattern. All these results are in good agreement with some recent data in the literature concerning the neopterin-induced intercellular adhesion molecule- 1 expression in rat alveolar epithelial cells L2 (70). On the basis of these results of ours obtained in vitro and concerning the stimulatory effects of some ranopterin fractions - Pt-6$\mathrm{COOH}$ and neopterin - on the entire bone marrow hematopoiesis (macrophage/granulocyte and stromal cell lines including) our studies in this direction have been continued as experiments in vivo.

\section{On the putative in vivo influence of ranopterin neopterin}

We have shown as early as 1968 that a pteridine derivative with high biological activity was isolated from the skin of Rana ridibunda and applied in vivo on the experimental mice (21). It was concluded that this pteridine preparation probably accelerate the processes of cell proliferation and differentiation of some cell lines in the hematopoietic system. Jacobson and Simpson (59) also identified the fluorescent substance isolated from the wings of buterflies as leucopterin and established the changes in the hematopoiesis under the biological action of this pteridine fraction. Busnel et al. (71) investigated the high biological activity of isoxantopterin-oxycarbonic acid, in the scales of fish. Hadjioloff et al. (26) examined the cellular lymph nodes responses after in vivo administration of some ranopterin fractions and showed the rapid increase in the values of the lymphoplasmocytes as an indication for immunogenic action of the ranopterins.

We have investigated the in vitro (51) and in vivo (52) influences of the exogenous ranopterin fraction-neopterin-on the lymphoproliferative, immunogenic and mitogenic lymphocyte responses in mice. It was found previously that in the liquid mouse long-term bone marrow cultures, exogenously treated by ranopterin neopterin, the one of the stim- ulated cell population was this of the small marrow lymphocytes-with intensively stained cytoplasmic RNP-granules (51). These results of ours could be discussed in the light of other data $(26,47)$ demonstrating a pronounced cell proliferation in the socalled B-zones of the mouse lymph nodes (with a high number of plasmocytes)-after in vitro and in vivo treatment with some ranopterin fractions.

Our recent data strongly suggest that the in vivo (i. p.) application of the ranopterin fraction-neopterinin mice (at a dose of $25 \mu \mathrm{g}$ per animal) induced lymphocyte proliferation in the spleen and increased responsibility of spleen lymphocytes to the T-cell mitogens (52). Flow cytometric analysis on the peripheral blood lymphocytes was also performed in the same experimental conditions using mice $\mathrm{CD} 3+\mathrm{T}$ lymphocytes marker (conjugated with Phycoerythrin) and FITC-conjugated marker for the surface IgG on B cells. The results obtained from the flow cytometric analysis show that the in vivo neopterin treatment of mice induced an increase of the whole blood CD3+T lymphocytes, simultaneously with expressed lymphocytosis in the peripheral blood of neopterin-treated mice. In the blood smears of neopterin-treated animals as well as in their spleen histological preparations and electronograms one can see a high number of lymphoblasts (probably Timmunoblasts; Fig. 6). Thus a significant stimulatory effects of the exogenous ranopterin neopterin on the cell-mediated immune activation (spleen Tlymphocytes responsibility to the T-cell mitogens including) suggest that this ranopterin fraction could be examined as a source of new preparations in states of immunodeficiency and/or immunosuppression. On the other hand, it is generally accepted that macrophages synthesize neopterin as a result of stimulation by cytokines derived from activated Tcells, such as interferon-g $(57,72,73)$. Though the biological function of neopterin remains unclear, elevation of its contents in body fluids have been reported in patients with various immune-related diseases, as well as in patients with viral infections such as HIV $(63,74-80)$. In turn, interferon-g stimulates neopterin production in human monocytes/ macrophages, and a neopterin concentration in body fluids is a sensitive indicator of the activation of cellmediated immunity $(63,72,81)$.

In all cases of neopterin-induced T-cell activation as well as in the cases of bone marrow and stromal cells stimulation-under the in vitro and in vivo influence of exogeneous treatment by ranopterins (Pt-6$\mathrm{COOH}$, neopterin) the fact could be generally considered that pteridines derivatives and especially neopterin shows some structural similarity to gua- 


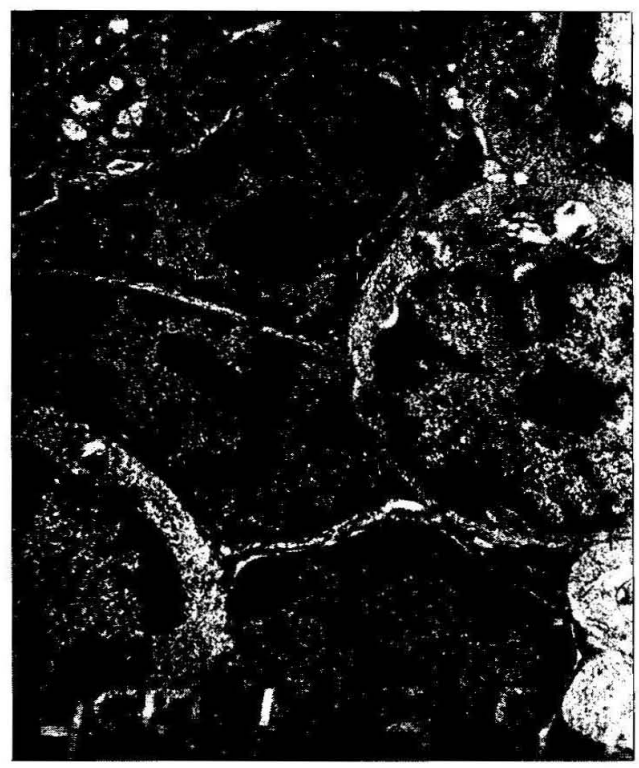

Figure 6. Neopterin-induced lymphoproliferation in the spleen of mice with the prevalence of euchromatin in blast cells nuclei, active nucleoli and polyribosomes in the cytoplasms (Opton electron microscope; $\times 65,000$ ).

nosine triphosphate (GTP) $(57,82)$. In parallel, interferon-g activated macrophages secrete neopterin and 7,8-dyhydroneopterin $(72,83,84)$ synthesized from GTP, which is in a first step enzymatically cleaved by the GTP-cyclohydrolase I to 7,8-dihydroneopterin triphosphate (85). We supposed (49) that exogenously added pteridines/ranopterins to the cell cultures, as a small molecules, generally penetrated through the cell and nuclear membranes thus affecting the cellular/nuclear metabolism including cellular proliferation and differentiation in insufficiently clarified biological ways-probably after an increase of the intracellular GTP concentrations $(51,53,57)$. By contrast, colchicine and colchicine derivatives (colcemide) are able to inhibit T-cell activation within the cellular immune response as well as interferon-g and neopterin production in human peripheral blood mononuclear cells (86). Recently we have shown the strongest activation of nitric oxide synthase (NOS) established in a population of large and mediumsized mouse peritoneal macrophages and a pronounced NOS activity in one population of mediumsized and small mouse bone marrow macrophages (Fig. 7), under the in vivo influence of the ranopterin fraction neopterin-applied at the same experimental conditions as described in our previous models (52). We concluded that the enhanced NOS macrophageal activity under the in vivo action of exogenously applied ranopterin neopterin could be due to both: directly to pterin (tetrahydrobiopterin$\mathrm{BH} 4)$ requirement of murine macrophage NOS in

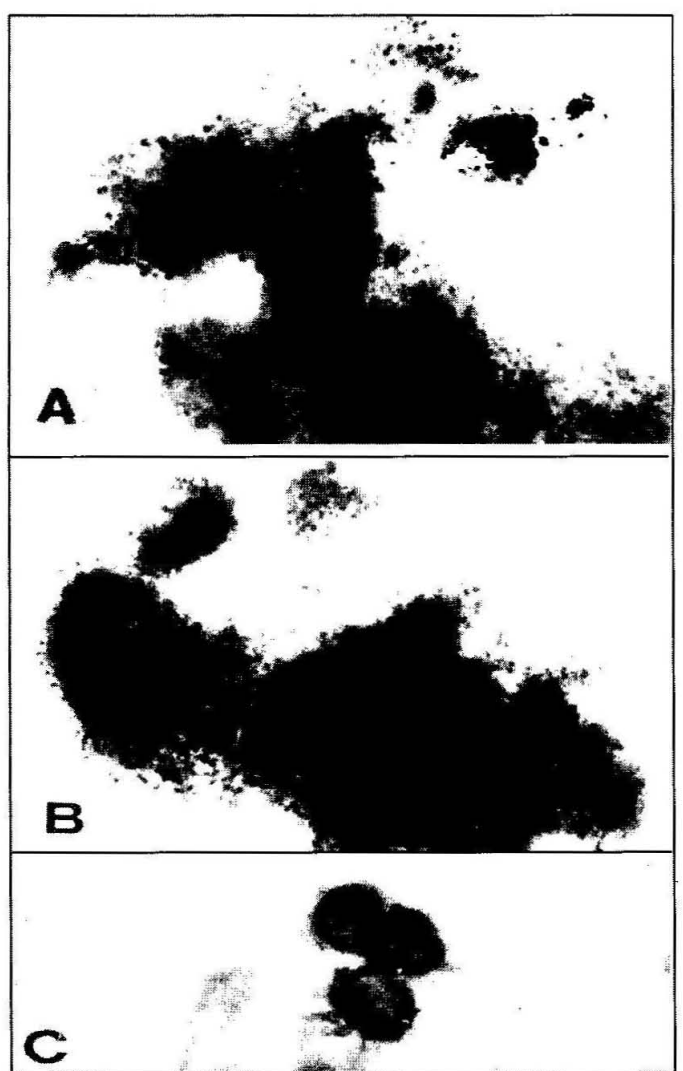

Figure 7. Nitric oxide synthase (NOS) activity in the cytoplasms of murine peritoneal macrophages-activated after in vivo treatment by the ranopterin-neopterin $(\mathrm{A}, \mathrm{B})$; NOS-positive small- and medium-sized bone marrow macrophages following intravital treatment by neopterin. (Hope and Vincent method, 1989, in our modification; $\times 1,250$-Immersion).

a concentration-dependent fashion and/or indirectlythrough the stimulation of the synthesis of cytokines (cytokine-stimulating pteridine biosynthesis in human monocytes/macrophages; ref. 7). Schobersberger et al. (87) showed that the pteridine compound neopterin is a stimulus for inducible NOS (iNOS) gene expression in rat vascular smooth muscle cells in vitro. The authors speculated that in this way (induction of iNOS) neopterin enhances the macrophage-induced extracellular toxicity and this might be of relevance for situations associated with excessive release of cytokines, neopterin and nitric oxide (NO), as is observed in septic shock. The mechanisms whereby neopterin stimulates in vitro iNOS gene expression and influenced/activated NO synthesis remained unclear but it is conceivable (88) that neopterin exhibits these effects through activation of transcription factor nuclear factor-kB (NF$\mathrm{kB}$ ). Hoffmann et al. (88) concluded that neopterin activates the translocation of NF-kB subunits to the nucleus br modulating the intracellular redox state. 
These data correlate with the findings of other authors that neopterin-derivatives produced from activated macrophages have a similar impact on NF$\mathrm{kB}$ (89). Induction of programmed cell death by these substances $(90,91)$ was also most likely due to the stimulation of iNOS gene expression and NO synthesis $(52,92-94)$ and thus macrophage-derived neopterin is potentially involved in the basic pathological processes such as atherogenesis (94). It is also interesting fact that in vivo, neopterin and proinflammatory cytokines interferon-g and TNF-a, are closely correlated concerning their synthesis, secretion and biological effects as well as their proapoptotic behavior (46, 90, 91, 94-96). Moreover ,data of Hoffmann et al. (94) revealed a dose-dependent effect of neopterin on TNF-a gene expression.

Recent data suggesting that the pteridines neopterin and 7,8-dihydroneopterin as well as the proinflammatory cytokines like TNF-a and interferon-g are common events in situations associated with an increased cellular immune system and macrophageal activity $(52,53,65,67,74,77,81)$ gave us ideas to study the potential protective effect of exogenously applied ranopterin fraction neopterin on the experimentally induced Graffi tumors in hamsters (55). The results pointed out the best protective effect of the ranopterin neopterin against the neoplasia development and tumor progression in cases when experimental tumor-bearing animals were neopterin-pretreated (a single neopterin application, 21-42 days before the tumor implantation at a dose $30 \mu \mathrm{g}$ per animal). The precise mechanisms by which the neopterin pretreatment could modify tumor growth are probably indirect-by activation/pre-activation of the host cell-mediated immunity $(52,53)$ : one population of small cytotoxic T-lymphocytes with RNPgranules in their cytoplasms appeared in a high percent in the peripheral blood smears of pre-treated by neopterin tumor-bearing animals (Fig. 8). In previous studies $(97,98)$ we have demonstrated that this small cytotoxic T-lymphocytes population directly participates in the cytotoxic/immunogenic antitumor mechanisms in cancer patients as well as in preneoplasias (Fig. 8C, D). In all these cases one can see the loss of cytoplasmic RNP from the cytoplasms of small cytotoxic lymphocytes in cytological and/or peripheral blood smears of cancer patients and tumor-bearing animals which gave us ideas about probable direct participation of small T-lymphocytes cytoplasmic RNP in the direct tumor cells cytolysis (Fig. 8A, B; E. Zvetkova, G. Kostov, I. Zvetkov, I. Valkov, unpublished). Yet we supposed that the potent antitumor effector T-cells could be CD8, also responsible for the direct lysis of SIV-

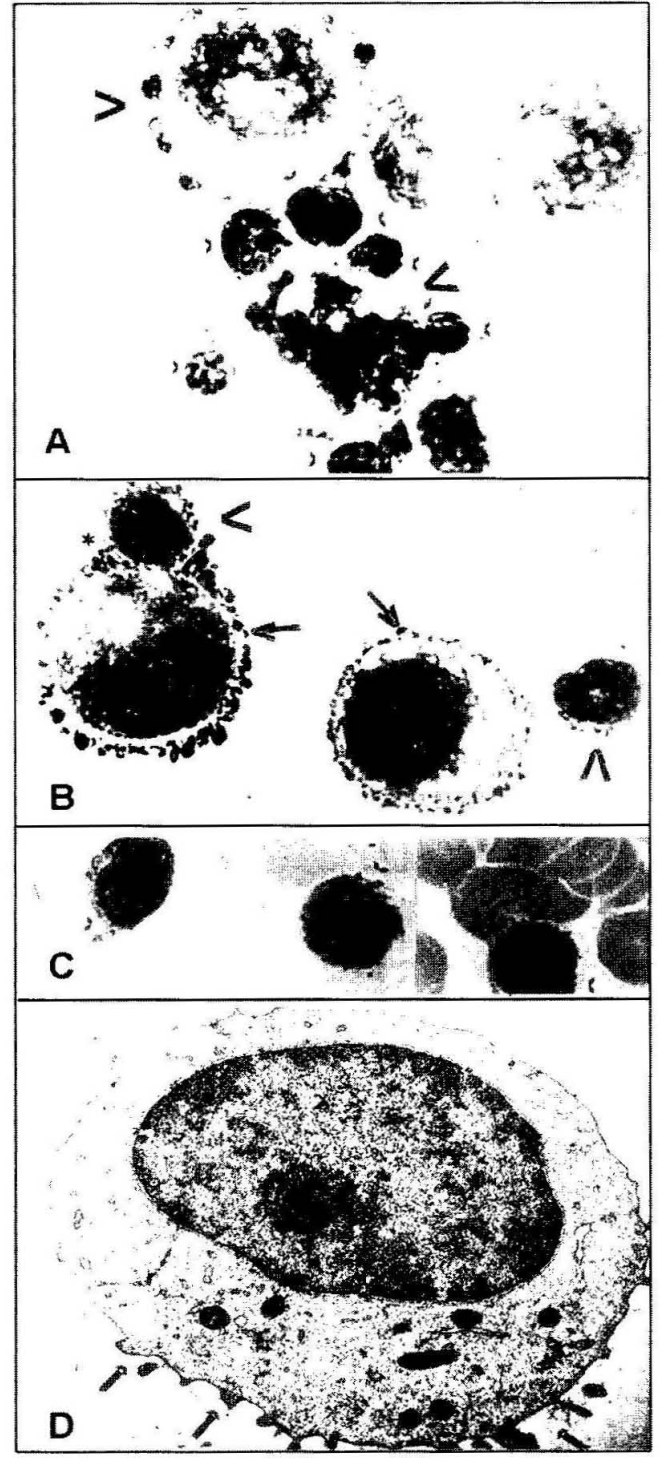

Figure 8. A: Cancer cells (arrowheads) and small lymphocytes (small arrowheads) interrelationships: small lymphocytes forming rosette-like structure around one tumor cell; B: cancer cells (arrows), small lymphocytes (arrowheads) and their relationships on the level of cytoplasmic RNP $\left(^{*}\right)$ which are unstained in places of cell to cell contacts (a possible influence of integrins or other biologically active substances on the cell membranes permeability could be disscussed-Zvetkova et al., unpublished). Cytological smears, stained by the method of Zvetkova and Zvetkov, ref. 99 ( $\times 600)$; C: small lymphocytes from the peripheral blood of tumor-bearing animals, with reduction of cytoplasmic RNP, by clasmatoses (arrowheads); blood smears stained by the same method $(\times 600)$ D: clectronograms of cancer-patient lymphocytes with abundant ribosomes-containing clasmatoses (arrows) at the cytoplasm periphery (Opton electron microscope, $\times 6,000$ ).

infected cells (inhibiting SIV-virus replication through the release of soluble cellular antiviral factors; ref. 80). As it is demonstrated in Fig. 8A and B, it is possible that T-lymphocytes/tumor cells interactions 
in cancer patients and tumor-bearing animals could be also mediated by soluble antitumor factor(s) released from the T-cells cytoplasmic RNP, moreover that the released of CD8 cell-derived antiviral/ supressive factor(s) are more common, yet unidentified, and/or active on different immunodeficiency viruses (80) (why not on these involved in the pathogenesis of some tumors and leukaemias; refs. 55,88 ). In addition, a direct antitumor action of the neopterin-activated in vivo and NO-producing mononuclear (monocyte/macrophage) populations/subpopulations could be also discussed (51-53) as a possible cellular mechanism of protection against tumor growth and development.

\section{Acknowledgment}

The author would like to thank to the European Commission-Directorate general XII, for the financial support under Contract ERBCIPDCT940253 from the Program PECO 1994 (Coordinator: Prof. Dr. P.G. Pelicci, European Institute of Oncology, Milan, Italy); and to Elena Nikolova and Maja Svetoslavova for the discussions and technical assistance.

\section{References}

1. Hopkins F. G. Note on a yellow pigment in butterflies. Nature 1889; 40: 335.

2. Purrmann R. Konstitution und Synthese des sogenannten Anhydroleukopterins. Justus Liebigs Ann Chem 1941; 548: 284-292.

3. Rembold H., Buschmann L. Struktur und Synthese des Neopterins. Chem Ber 1963; 96: 1406-1410.

4. Rembold H., Buschmann L. Untersuchungen über die Pteridine der Bienenpuppe (Apis mellifica). Justus Liebigs Ann Chem 1963; 662: 72-82.

5. Blakley R. L. Natural occurrence of pterins and folate derivatives. In: The Biochemistry of Folic Acid and Related Pteridines (Pfleiderer W., Taylor E. C., eds.), North-Holland Publications, Amsterdam, 1969, pp 857.

6. Forrest H., Van Baalen C. Microbiology of unconjugated pteridines. Annu Rev Microbiol 1970; 24: 91108.

7. Ziegler I., Harmsen R. The biology of pteridines in insects. Adv Insect Physiol 1969; 6: 139-62.

8. Hadjioloff A. I. Phenomenes de fluorescence determines par la lumiere de Wood au niveau de la peau de la grenouille. Bull Histol Appl 1929; 6: 37-47.

9. Hadjioloff A. I. Les chromatophores bleus dans la peau de la grenouille. Compt Rend Soc Biol, Paris, 1929; 100: 669-673.

10. Hadjioloff A. I. A propos des phenomenes de fluorescence determines par la lumiere de Wood au niveau des organes de l'homme et des animaux, a l'etal frais, apres autolyse et putrcfication et apres calcination. Compt Rend Soc Biol, Paris, 1929; 102: 779.

11. Hadjioloff A. I. La methode luminoscopique dans la biologie et la medecine. (Conference tenue a Warsovie, le 27 avril, 1937). Folia morphologica (Warszawa) 1937; 7: 192-208.

12. Hadjioloff A. I., Krestev T. Phenomenes de fluorescence determines par la lumiere de Wood au niveau de la peau des poissons. Bull Histol appl 1932; 12: 153-158.

13. Hüttel R., Sprengling G. Uber Ichthyopterin, einen blaufluoreszirenden Stoff aus Fischhaut. Annalen der Chemie 1943; 554: 69-82.

14. Hama, T. Substances fluorescentes de type pterinique dans la peau ou les ycux de la grenouille (Rana nigromaculata) et leurs transformations photochimiques. Experimentia 1953; 9: 299-300.

15. Günder, J. Über den papierchromatographischen und fluorestenzmikroskopischen Nachweis von Pterin und Riboflavin bei Amphibien und Reptilien. Naturwissenschaften 1953; 40: 20-21.

16. Günder, J. Nachweis und Lokalisation von Pterin und Riboflavin in der Haut von Amphibien und Reptilien. Z Vergl Physiol 1954; 36: 78-114.

17. Goto, T. Isolation and characterization of some fluorescent substances in the skin of the frog, Rana nigromaculata. Dobutsugaku Sassahi 1959; 68: 286-280.

18. Goto, T. Über einen blaufluoreszierenden Stoff "Buffochrom", seine Isolierung aus der Haut einer Krote Bufo vulgaris und sein Verhalten in den Entwicklungestadien. Japanese J Zool 1963; 14: 83-90.

19. Goto, T. Fluoreszierender Stoff aus Bufo vulgaris: Konstitutionsaufklärung des Pteridins "Buffochrom". Japanese J Zool 1963; 14: 91-95.

20. Hadjioloff A. I., S. Atzev:Sur la luminescence propre des cellules et des tissus chez les vertebres inferieurs en rapport avec les pterines. C R Assoc Anat 1955; 42: 639-652

21. Atsev, S., A. I. Hadjioloff. On the biological action of pterins from the skin of Rana ridibunda. Bull Inst Morphol 1968;13:89-99.

22. Hadjioloff A. I, E. Zvetkova. Contribution a la fluorescence propre de la peau des amphibiens (Bombina variegata et Rana esculenta). Bull Assoc Anat Paris, 1970; 148: 384-387.

23. Hadjioloff A. I., E. Zvetkova. Layers with proper fluorescence in the derma of Amphibia.-Compt Rend Acad Bulg Sci 1978; 3: 481-484.

24. Hadjioloff A. I., E. Zvetkova. Intravital fluorochromation of proper fluorescentdermal layers in Amphibia by alisarine red and tetracycline. Compt Rend Acad Bulg Sci 1978; 31:603-606.

25. Hadjioloff A. I., E. Zvetkova. On the histochemistry of the proper fluorescent structures in the derma of Amphibia. Compt Rend Acad Bulg Sci 1978; 31: 759762.

26. Hadjioloff A. I., Shivatcheva T. M., Veltcheva M. S., Dikov A. L. On the biological action of ranopterines. Compt Rend Acad Bulg Sci 1981; 34: 229-232.

27. Hadjiolov, A.I., E. Zvetkova. Fluorescent Properties of Cell and in Vertebrates and Humans. Publ House Bulg Acad Sci Sofia, 1989, pp.1-195. 
28. Bagnara, J. T. Chromatotropic homonc, peridines and amphibian pigmentation. Gen Comp Endoxrinol 1961; 1: 124-133.

29. Bagnara, J. T. Cytology and estophysiology of non-melanophore pigment cells. Int Rer Citol 1966; 20: 173205.

30. Hama T., M. Obika. On the nature of some fluorescent substances of pterin type in the adult skin of toad, Bufo vulgaris formosus. Experientia 1958; 14: 182-184.

31. Hama, T., M. Obika. Histological distribution of pterins in the skin of bullfrog. Anat Res 1959: 134: 25-36.

32. Hama, T. The relation between the chromatophores and pterin compounds. Ann N Y Acad Sci 1963; 100: 977982.

33. Obika, M. Association of pteridines with amphibian larval pigmentation and their biosynthesis in developing chromatophores. Develop Biol 1963; 6: 99-112.

34. Obika, M., J. T. Bagnara. Pteridines as pigments in amphibia. Science 1964; 143: 485-495.

35. Obika, M. Morphology and biochemistry of pterinosomes in lower vertebrates. In: Chemistry and biology of pteridines. (ed. W. Pfleiderer). International Academic Printing Co, Tokyo, 1970, 413-423.

36. Bagnara, J. T., M. Obica. Comparative aspects of inegumental pteridine distribution among amphibians. Comp Biochem Physiol 1965; 15: 33-49.

37. Matsumoto, J. Studies on fine structure and cytochemical properties of erythrophores in Xiphophorus helleri, with special reference to their pigment granules. J Cell Biol 1965; 27: 493-504.

38. Matsumoto, J. Role of pteridines in the pigmentation of chromatophores in cypridin fish. Japan J Zool 1965; 14: 45 .

39. Matsumoto, J., M. Obika. Morphological and biochemical characterization of goldfish erythrophores and their pterinosomes. J Ccll Biol 1968; 39: 233-250.

40. Hadjioloff A. I., A. Manina, E. Zvetkova, A. Boyadjieva-Michailova, Z. Barbolova. Ultrastructural investigations on the dermal chromatophores in Amphibia. Compt Rend Acad Bulg Sci 1977: 30: 1507-1510.

41. Bagnara, J. T. Pigment cells. In: Biology of the Integument. 2. Vertcbrates Berciter-Hahn H., A.G. Matoltsy, S. Richards, Eds.) 1986, Springer-Verlag, Heidelberg, pp. 136-148.

42. Hadjioloff, A.I., E. Zvetkova, L. Kancheva, S. Yancv, Y. Martinova, M. Veltcheva. Incorporation of labelled biogenic amines and their precursors in the skin of amphibia-pigment cells. Compt Rend Acad Bulg Sci 1980; 33: 1123-1126.

43. Hadjioloff, A. I., L. Kancheva, Y. Martinova, E. Zvetkova, M. Veltcheva. Autoradiographic study of catecholamine metabolism in amphibian dermis. Folia Morphologica 1981; 29: 56-58.

44. Hadjioloff A. I., M. S. Veltscheva, Y. S. Martinova, E. Zvetkova, L. S. Kancheva, S. G. Yanev. Recherches autoradiographiques sur la synthese du melanine dans la peau et dans le foie d'Amphibia. Arch Union Med Balk Bukarest) 1983; 21: 90-93.

45. Zvetkova E., A. I. Hadjioloff, M. Anastassova-Kristeva, L. Kancheva. Uptake of P in autofluorescent calcified structures of amphibian dermis. Compt Rend Acad
Bulg Sci 1979; 30: 1351.

46. Werner-Felmayer, G., E.R. Werner, D. Fuchs, A. Hausen, G. Reibnegger, H. Wachter. Tumour necrosis factor-a and lipopolysaccharide enhance interferoninduced tryptophan degradation and pteridine synthesis in human cells. Biol Chem Hoppe-Seyler 1989; 370: 1063-1069.

47. Shivatcheva, T., A. I. Hadjioloff, A. Dikov. In vitro blast transformation of lymphocytes under the action of ranopterines. Compt Rend Acad Bull Sci 1982; 35: 14391442.

48. Tschesche R., Korte F. Dic Konstitution des Ichthyopterins. Chem Berichte 1951; 84: 801-809.

49. Zvetkova E., E. Janeva, E. Nikolova, et al. Hemopoictic colony-stimulating activity of ranopterines in murine bone marrow agar cultures. Compt Rend Acad Bulg Sci 1991; 44: 91-94.

50. Zretkora E., E. Ianeva, A. Dikov, A. I. Hadjioloff. Ranopterine with MG-CSF-like activity in murine bone marrow agar cultures. Cell Prolif 1992; 25: 498.

51. Zvetkova E., I. Tsenov, E. Katzarova, et al. In vitro proliferation of mouse bone marrow lymphocytes and stromal macrophages under the biological action of ranoptarin (neopterin). Compt Rend Acad Bulg Sci 1995; 48: $81-84$

52. Zvetkova, E., E. Katzarova, I. Chowdhury et al. Activation and NO secretion pattern of murine macrophage subpopulations after in vivo administration of ranoptcrin neopterin. Comp Rend Acad Bulg Sci 1996; 49: 113-116.

53. Zvetkova, E., R. Toschkova, K. Kovatcheva, et al. Lymphoproliferation and immune response induced by ranopterin neopterin in mice. Compt Rend Acad Bulg Sci 1996; 49: 117-120.

54. Zvetkova E., E. Katzarova, E. Ianeva, et al. CSA production in murine long term bone marrow cultures after in vitro treatment with ranopterines. Acta Morphologica et Anthropologica 1997; 4: 59-61.

55. Zvetkova E., R. Toshkova, V. Ralchevsky, et al. Protective effect of ranopterin neopterin on experimentally induced Graffi tumours in hamsters. Pteridines 1998; 9: $196-200$

56. Zvetkova E., Jelinek J. Methylene blue-fast green staining of hemopoietic colonies in agar cultures. Gegenbaurs Morphol Jahrb 1989; 135: 779-793.

57. Schoedon, G., J. Troppmair, A. Fontana, C. Huber H.C. Curtius, A. Niederwieser. Biosynthesis and metabolism of pterins in peripheral blood mononuclear cells andleukemia lines of man and mouse. Eur J Biochem 1987; 166: 303-310.

58. Milstein S., S. Kaufman, K. Tanaka. In: Chemistry and Biochemistry of Pteridines (Eds. H.-C. Curtius, S. Ghisla, N. Blau), Walter de Gruyter, Berlin-New York, 1990, pp. 505-510.

59. Jacobson W., D. Simpson. The fluorescence spectra of pterins and their possible use in the elucidation of the antipernicious anaemia factor. Biochem J 1946; 40: 9. 14.

60. Benabdallah K., Boivin P., Dhermy D. The synthesis and accumulation of membrane protein 4.1 in Friend erythroleukaemia cells. Biol Cell 1991; 71: 273-280. 
61. Taraboletti, G., P. Borsotti, R. Chirivi, et al. Effect of all trans-retinoid acid (ATRA) on the adhesive and motility properties of acute promyelocytic leukemia cells. Int J Cancer 1997; 70: 72-77.

62. Zimmerman G.A., S.M. Prescott, T.M. McIntyre. Endothelial cell interactions with granulocytes:lethering and signaling molecules. Immunol Today 1992; 13: 93 99.

63. Fuchs, D., A. Hausen, G. Reibnegger, E.R. Werner, M.P. Dierich, H. Wachter. Neopterin as marker for activated cell-mediated immunity:application in HIV infection. Immunol Today 1988; 9: 150-155.

64. Luna-Casado L., A. Diez-Ruiz, F. Gutierrez-Gea, et al. Increased mononuclear cells expression of adhesion molecules in alcoholic cirrhosis:its relation to immune activation. I Hepatology 1997; 27: 477-483.

65. Tilz G., A. Diez-Ruiz, G. Baicr-Bitterlich, U. Demel, H. Wachter, D. Fuchs. Soluble receptors for tumor necrosis factor and neopterin as parameters of cell-mediated immune activation. Hematology 1996; 1: 141154

66. Hoffmann G., S. Frede, S. Kenn, et al. Ncopterininduced Tumor Necrosis Factor-a synthesis in vascular smooth muscle cells in vitro. Int Arch Allergy Immunol 1998; 116: 240-245.

67. Zangerle R., S. Steinhuber, M. Sarcletti, et al. Serum HIV-1 RNA levels compared to soluble markers of immune activation to predict disease progression in HIV-1-infected individuals. Int Arch Allergy Immunol 1998; 116: 228-239.

68. Denefle J. P., Q. L. Zhu, J. P. Lechaire. Dermal tracts in frog skin: fibronectin pathways for cell migration. Biology of the Cell 1987; 59: 219-226.

69. Iwata, A., M. Iwata, E. Nakano. Fibronectin-induced migration of melanophores in vitro in skales of medaka Oryzias latipes. Cell Tissue Res 1984; 238: 509-513.

70. Rieder, J., W.Schobersberger, D.Fuchs, et al. Neopterin induces intercellular adhesion molecule- 1 expression in rat alveolar epithelial cells L2. Pteridines, in press.

71. Busnel, R., P. Chauchard, H. Mazone, et al. Action de la fluorescence et de lacide isoxanthopterine carboxylique sur les test $\mathrm{d}$,avitaminose $\mathrm{Bl}$ du pigeon et du flagelle Polytomella caeca. C R Acad Sci 1944; 218 : 609-610.

72. Huber C., R. Batchelor, D. Fuchs, et al. Immune response associated production of neoptcrin: Release from macrophages primarily under control of interferon-gamma. J Exp Med 1984; 165: 310-316.

73. Wachter, H., D. Fuchs, A. Hausen, G. Reibnegger, G. Weiss, E. R. Werner, G. Werner-Felmayer. Neopterin: Biochemistry, methods, clinical application. Berlin-New York, Walter de Gruyter, 1992, pp. 1-294.

74. Fuchs D., T. Spira, A. Hausen, et al. Neopterin as a predictive marker for disease progression in human immunodeficiency virus type I infection. Clin Chem 1989;35:1746-1749.

75. Fuchs D., G. Weiss, G. Reibnegger, et al. The role of neopterin as a monitor of cellular immune activation in transplantation, inflammatory, infectious and malignant diseases. Crit Rev Clin Lab Sci 1992; 29: 307-341.

76. Reibnegger, G., D. Fuchs, D. Fuith, et al. Neopterin as a marker for activated cell-mediated immunity: application in malignant disease. Cancer Detect Prevent 1991; 15: 483-490.

77. Tilz G., A. Diez-Ruiz, G. Baier-Bitterlich, et al. Soluble receptors for tumor necrosis factor and neopterin as parameters of cellmediated immune activation. ACI International 1997; 9: 110-118.

78. Baier-Bitterlich, G., D. Fuchs, R. Zangerle, et al. transActivation of the HIV type 1 promoter by 7,8-dihsdroneopterin in vitro. AIDS Res Human Retroviruse 1997; 13: 173-178.

79. Baier-Bitterlich G., D. Fuchs, H. Wachter. Chronic immune stimulation, oxidative stress, and apoptosis in HIV infection. Biochem Pharmacol 1997; 53: 755 763.

80. Spring M., Ch. Stahl-Hennig, Th. Nisslein, et al. Suppression of viral replication in a long-term nonprogressing Rhesus Macaque experimentally infected with pathogenic Simian Immunodeficiency Virus (SIV). Clin Immunol Immunopathol 1998; 87: 101-105.

81. Wachter, H., D. Fuchs, A. Hausen, et ai. Neopterin a marker for activation of cellular immunity:Immunologic basis and clinical application. Adv Clin Chem 1989; $2^{-}$ 81-141.

82. Blau N., D. Schoedon, H. C. Curtius. Biosynthesis and significance of neopterin in the immune system. Europ J Cancer Clin Oncol 1989; 25: 603-605.

83. Bitterlich G., G. Szabo, E.R. Werner, et al. Selective induction of mononuclear phagocytes to produce neopterin by interferons. Immunobiology 1988;176:228 235.

84. Werner E.R., G. Werner-Felmayer, D. Fuchs, et al. Parallel induction of tetrahydrobiopterin biosynthesis and and indoleamine 2,3-dioxygenase activity in human cells and cell lines by interferon-g. Biochem J 1989; 262: 861-866.

85. Werner E. R., G. Werner-Felmayer, D. Fuchs, et al. Tetrahydrobiopterin biosynthetic activities in human macrophages, fibroblastsTHP-1 and T-24 cells. J Biol Chem 1990; 265: 3189-3192.

86. Altindag Z., G. Werner-Felmayer, G. Sahin, H.Wachter, D. Fuchs. Colchicine derivatives inhibit neopterin production in human peripheral blood mononuclear cells (HBMC). Clin Exp Immunol 1997; 107: 574-577.

87. Schobersberger, W., G. Hoffmann, J. Grote, H. Wachter, D. Fuchs. Induction of inducible nitric oxide synthase expression by neopterin in vascular smooth muscle cells. FEBS Lett 1995; 377: 461-464.

88. Hoffmann G., W. Schobersberger, S. Frede, et al. Neopterin activates transcription factor nuclear factor- $k B$ in vascular smooth muscle cells. FEBS Lett 1996; 391: 181-184.

89. Wirleitner, B., G. Baier-Bitterlich, G. Hoffmann, et al. Neopterin derivatives to activate NF-kB. Free Radical Biol Med 1997; 23: 177-178.

90. Kojima, S., T. Icho, H. Mori, T. Arai. Enhancing potency of neopterin toward B-16 melanoma cell damage induced by UV-A irradiation and its possible applications for skin tumor treatment. Anticancer Res 1995; 15: 1975-1980.

91. Fuchs, D., G. Baier-Bitterlich, I. Wede, H. Wachter. 
Reactive oxygen and apoptosis. In: Oxidative Stress and the Molecular Biology of Antioxidant Defenses. Cold Spring Harbor Laboratory Press, 1997, 139-167.

92. Albina, J. E., S. Cui, R. B. Mateo, J. S. Reichner. Nitric oxide-mediated apoptosis in murine peritoneal macrophages. J Immunol 1993; 150: 5080-5085.

93. Schobersberger, W., G. Hoffmann, P. Hobisch-Hagen, et al. Neopterin and 7,8-dihydroneopterin induce apoptosis in the rat alveolar epithelial cell line L2. FEBS Lett 1996; 397: 263-268.

94. Hoffmann G., S. Kenn, B. Wirleitner, et al. Neopterin induces nitric oxide-dependent apoptosis in rat vascular smooth muscle cells. Immunobiology 1998; 199: 6373.

95. Baier-Bitterlich, G., D. Fuchs, C. Murr, et al. Effect of neopterin and 7,8-dihydroneopterin on tumor necrosis factor-a induced programmed cell death. FEBS Lett
1995; 364: 234-238.

96. Diez-Ruiz, A., G.P. Tilz, R. Zangerle, G. Baier-Bitterlich, H. Wachter, D. Fuchs. Soluble receptors for tumor necrosis factor in clinical laboratory diagnosis. Eur J Haematol 1995; 54: 1-8.

97. Zvetkova E., S. Koshucharov, A. I. Hadjioloff. Cytochemistry of nucleoproteins (RNP and DNP) and some cationic proteins in the peripheral blood leukocytes of patients with lung cancer. Folia Haematol 1979; 106: 205-223.

98. Zvetkova E., G. Kostov, A. I. Hadjioloff, I. Zvetkov. Sur la cytochimie des leucocytes chez les cancereux et les precancereux. Arch Union Med Balk 1984; 22: 140142.

99. Zvetkova E., I. Zvetkov. A cytological method for the simultaneous staining of nuclcoproteins and some cationic proteins. Acte Histochem 1976; 57: 1-13. 